American Medical Journal 3 (2): 194-202, 2012

ISSN 1949-0070

(C) 2012 Science Publications

\title{
Comparative Analysis of UGT1A9 Genetic Polymorphisms between Chinese Han and Tibetan Populations
}

\author{
${ }^{1}$ Wei Yan, ${ }^{2}$ Jian Cui, ${ }^{1}$ Yuewen Wang, \\ ${ }^{1}$ Xiaoqing Zhang, ${ }^{1}$ Fangfang Yang, ${ }^{1}$ Er Fei Chen, ${ }^{1}$ Min Wang and ${ }^{1}$ Jin Yang \\ ${ }^{1}$ National Engineering Research Center for Miniaturized Detection System, \\ College of Life Sciences, Northwest University, Xi'an, Shaanxi 710069, China \\ ${ }^{2}$ Clinical Medical Lab, Qinghai Hospital of Traditional Chinese Medicine, Qinghai 810000, China
}

\begin{abstract}
Although various polymorphisms have been identified in the UGT1A9 gene in the main sorts of ethnic groups in the world, no investigations have been focused on the Chinese Tibetan populations and the comparison between Chinese Tibetan and Han populations to date. This study was designed to systematically compare genetic differences between the two populations. We investigated the functional regions of UGTIA9 in 200 unrelated healthy Chinese volunteers, comprising 100 Tibetan and 100 Han individuals from Qinghai and Shaanxi, respectively, by using direct sequencing. A total of 21 different genetic variants, including 7 novel variants were identified. According to the results of comparative analysis, the allele frequencies of three common variants $(-1888 \mathrm{~T}>\mathrm{G}$, 95246T $>\mathrm{C}, 96292 \mathrm{C}>\mathrm{T})$ were significantly different between Tibetan and Han populations $(\mathrm{p} \leq 0.05)$. However, there were no differences of linkage disequilibrium patterns, haplotype structures and htSNPs between the two populations. UGT1A9*1b was the prevalent defective alleles in Chinese population. In addition, $-1888 \mathrm{~T}>\mathrm{G},-1819 \mathrm{~T}>\mathrm{C},-441 \mathrm{C}>\mathrm{T}$ affected the binding of transcriptional factors and four of the missense mutations (P361L, N397H, P448L and Y483D) were highly conserved among the three different species (Homo sapiens, Rattus norvegicus and Danio rerio). In short, there are significant differences of genetic information of UGTIA9 between Chinese Tibetan and Han populations. The determined genetic information of UGT1A9 in Chinese Tibetan and Han populations might serve as a baseline for larger studies on pharmacogenomics and also provide important data for the advance of personalized medicine in Chinese Han and Tibetan populations.
\end{abstract}

Key words: Tibetan, haplotype, LD, polymorphism, UGT1A9

\section{INTRODUCTION}

The human UDP-Glucuronosyl Transferases (UGTs) is one of phase II drug-metabolizing enzymes that catalyze the glucuronidation of a variety of endogenous and other exogenous compounds, including drugs, carcinogens and other xenobiotics (Fujita et al., 2006). According to the primary amino acid sequence homology of UGT, they were categorized into two major families, UGT1 and UGT2 (Chouinard et al., 2006). The entire UGT1 family is derived from a single gene locus (UGT1A), located on chromosome 2 (2q37), spanning about $210 \mathrm{~kb}$, coding for nine functional proteins (UGT1A1, UGT1A3-UGT1A10) and three pseudogenes (Gong et al., 2001). The UGT2 family can be further divided into two subfamilies, UGT2A and UGT2B, which are encoded by different genes clustered on chromosome 4q13-4q21.1 (Turgeon et al., 2000). The UGTIA isoforms share the identical exon 1 , while differing in exons 2-5, both of which are responsible for the specific expression of UGT1A isoforms (Araki et al., 2005). The regulation and expression of the UGT1A gene are tissue-specific, eg. UGT1A1, UGT1A3, UGT1A4, UGT1A6 and UGT1A9 (Strassburg et al., 1997; 1998; 1999) are hepatic tissuespecific, whereas UGT1A7, UGT1A8 and UGT1A10 are exclusively expressed in extrahepatic tissues such as mouth, esophagus, intestine, pancreas and colon (Ockenga et al., 2003; Strassburg et al., 1997; 1999; Vogel et al., 2002).

The UGT1A9 gene, a member of the UGT1 family, is both involved in the metabolism of endogenous estrogens and thyroid hormones, the exogenous chemicals and drugs such as phenol, acetaminophen,

Corresponding Author: Jin Yang, National Engineering Research Center for Miniaturized Detection System, College of Life Sciences, Northwest University, Xi' an, 386", Taibai North Road 229, Shaanxi 710069, China Tel: 86-29-88303446-851 Fax: 86-29-88303551 
propofol, propranolol, (Albert et al., 1999). The UGT1A9 gene is expressed specifically in liver, kidney, colon and esophagus (Albert et al., 1999; Tukey and Strassburg, 2000). To date, various polymorphisms have been identified in the UGT1A9 gene, resulting in decrease of UGT1A9 activities toward a variety of exogenous substances and affecting efficiencies of drug metabolisms. $-118(\mathrm{dT})_{9>10}(U G T 1 A 9 * 1 b)$, for example, is one of the most important polymorphisms in the promoter region of the UGT1A9 gene reported to be associated with the enhanced transcriptional activity of this gene (Yamanaka et al., 2004). This variant was reported (Carlini et al., 2005) to cause higher incidence of toxicity and poor tumor response. UGT1A9 polymorphisms influence $\mathrm{SN}-38 \mathrm{G}$ formation in liver microsomes (Han et al., 2006) and UGT1A9*1b genotypes might be important for SN-38 glucuronidation. In this regard, polymorphisms of UGT1A9 gene may exert a significant impact on the pharmacokinetics and toxicity of drugs.

China consists of 56 ethnic groups, among which Han accounts for $90.56 \%$ of the total Chinese population, yet Tibetan is a major minority. Up to now, no systematic investigations have been focused on polymorphisms, Linkage Disequilibrium (LD) pattern and haplotype structures of UGT1A9 in Tibetan population. Similarly, the genetic information comparison between Tibetan and Han is also rare. The genetic information may be different due to ethnic and spatial differences (Mehlotra et al., 2007). Polymorphisms, genotypes and haplotypes may collectively provide more effective aids for individualized treatment. In this study, in order to study and compare the identified genotypes, allele frequencies, LD pattern, haplotype structures and haplotype tagSNPs (htSNPs) of UGT1A9 in the Tibetan and Han groups, a comprehensive study on the genetic information in the Tibetan and Han populations was conducted, The determined genetic information of UGT1A9 in Chinese Tibetan and Han populations might serve as a baseline for larger studies on pharmacogenomics and also provide important data for the advance of personalized medicine in Chinese Tibetan and Han populations.

\section{MATERIALS AND METHODS}

Study populations: Two hundred healthy unrelated Chinese people from two different regions of the Chinese mainland were recruited in the study. Two hundred Chinese can be divided into two groups, one hundred Han volunteers from Yulin, Shaanxi province and one hundred Tibetan volunteers from Qinghai province. Each group includes 50 males and 50 females aging from 18-40 years. All participants provided their detailed information, so we can guarantee that the people in each group were of the same origin. All volunteers provided written consent for the use of their peripheral blood samples for experimental purposes and the present study was reviewed and approved by the ethics committee of Northwest University.

Polymerase Chain Reaction (PCR) and DNA sequencing: Systematic polymorphism screening was performed using PCR and direct sequencing. A $2 \mathrm{ml}$ sample of venous blood was collected from each subject. Genomic DNA was extracted from peripheral blood leukocytes of 200 subjects by the standard procedure (Fujita et al., 2006). The extracted DNA was dissolved in sterile distilled water and stored at $-80^{\circ} \mathrm{C}$ until PCR analysis. The promoter regions, all exons and 3'UTR of the UGT1A9 gene were amplified and directly sequenced using an ABI PRISM 3700 DNA analyzer (Applied Biosystems, Foster City, California, USA) using eight sets of primers. The obtained sequences were examined for the presence of variants using Sequencher software (version 4.10.1, Gene Codes Corporation, Ann Arbor, Michigan, USA). The A in the ATG translation start codon is denoted nucleotide +1 . The sequence of the complete UGT1A9 gene described in GeneBank (Gene ID: 54600) was used as a reference.

Statistics analysis: Allele and genotype frequencies were calculated by the counting method. The $\chi^{2}$ test or Fisher's exact test were used to compare allele, genotype frequencies between the Tibetan and Han populations. Statistical significance was set at $\mathrm{p}<0.05$. All the statistical works were implemented on the SPSS 16.0 platform. Haploview, based on the expectationmaximization method, was used to measure LD between each of two loci and to estimate the Lewontin's coefficients D' (Lewontin, 1988) and correlation coefficient $\mathrm{r}^{2}$ (Hill and Robertson, 1968). $\mathrm{r}^{2}$ of 0.8 was selected as a threshold for all analysis. The block structures and their haplotype frequencies were also estimated using Haploview version 3.2 (Stephens et al., 2001). htSNPs were selected using the Haploview version of the Tagger program.

Functional predictions: Polymorphisms in the promoter region may have an influence on Transcriptional Factors (TFs) binding to the specific sites, including sorts and amounts. Web-based TFSEARCH software was used to analyze the transcriptional factor binding to the promoter region. The normal and variant sequences were analyzed by the software, respectively. According to the analysis, the influence of the polymorphisms towards to TFs was speculated. As for non-synonymous variants, conservative assessment was performed on the web- 
based Protein BLAST software (http://blast.ncbi.nlm.nih.gov/) in three species which were Homo sapiens (h), Rattus norvegicus (r) and Danio rerio (d).

\section{RESULTS}

Identification of genetic variants in UGT1A9 in Chinese Tibetan and Han populations: In the Chinese Tibetan and Han populations, a total of 21 different genetic variants, including 7 novel variants, were detected in the promoter region, five exons, surrounding introns and 3'UTR of UGT1A9 (Table 1). $-2189 \mathrm{~T}>\mathrm{C}, \quad-1888 \mathrm{~T}>\mathrm{G}, \quad-1819 \mathrm{~T}>\mathrm{C}, \quad-441 \mathrm{C}>\mathrm{T},-$ $332 \mathrm{~T}>\mathrm{C},-118 \mathrm{delT}$ and $-40 \mathrm{C}>\mathrm{G}$ in the promoter region were detected, among them $-2189 \mathrm{~T}>\mathrm{C}$ and $40 \mathrm{C}>\mathrm{G}$ were novel yet $-40 \mathrm{C}>\mathrm{G}$ was specific to Han population with minor allele frequency $0.5 \%$, $2189 \mathrm{~T}>\mathrm{C}$ with minor allele frequencies $0.5 \%, 1.5 \%$, respectively, in Tibetan and Han populations. In the coding region, 9 variants were detected, including one novel nonsynonymous variant $(96399 \mathrm{~A}>\mathrm{C}, 397$ $\mathrm{N}>\mathrm{H}$ ) in one Tibetan subject in exon 4, two novel synonymous variant $(588 \mathrm{G}>\mathrm{T}, 95186 \mathrm{G}>\mathrm{A})$. Among these variants, two were synonymous variants and four were nonsynonymous variants. Besides, 94987T $>\mathrm{C}, 94990 \mathrm{~A}>\mathrm{C}$ and $95246 \mathrm{~T}>\mathrm{C}$ in the introns were also identified and $94990 \mathrm{~A}>\mathrm{C}$ was novel. In the 3'UTR, 100813T>G, 100836T >C, 100964G $>$ C,
$101044 \mathrm{~T}>\mathrm{C}$ and $101065 \mathrm{G}>\mathrm{C}$ were detected, including one novel $(100813 \mathrm{~T}>\mathrm{G})$ in one Han subject. Among the 21 variants, nine ones $1888 \mathrm{~T}>\mathrm{G}, \quad-1819 \mathrm{~T}>\mathrm{C}, \quad-332 \mathrm{~T}>\mathrm{C}, \quad-118 \mathrm{delT}$, 95246T $>\mathrm{C}, \quad 96292 \mathrm{C}>\mathrm{T} \quad(\mathrm{P} 361 \mathrm{~L}), \quad 100836 \mathrm{~T}>\mathrm{C}$, $100964 \mathrm{G}>\mathrm{C}$ and $101065 \mathrm{G}>\mathrm{C}$ were common SNPs (minor allele frequency $\geq 0.05$ ). Common polymorphic frequencies in the two ethnic groups were compared by statistical analysis. According to the statistical comparison, some of the polymorphic frequencies demonstrated significant differences between the two ethnic groups, such as $-1888 \mathrm{~T}>\mathrm{G}$, $\mathrm{p}=0.015 ; 95246 \mathrm{~T}>\mathrm{C}, \mathrm{p}=0.05 ; 96292 \mathrm{C}>\mathrm{T}, \mathrm{p}=0.008$.

Allele and genotype frequencies: The frequency of the different UGT1A9 alleles was listed in Table 2. Four different UGTIA9 alleles were identified based on discoverable polymorphisms in this study which were UGT1A9*1a, *1b, *1d and *1f. In Tibetan population, the frequent alleles were the wild-type allele *1a $(55.05 \%)$ and allele*1b (41.41\%). Alleles $* 1 \mathrm{~d}$ and $* 1 \mathrm{f}$ were detected with frequencies of $1.52 \%, 1.02 \%$, respectively. In the Han population, the frequent alleles were also the wildtype allele $* 1 \mathrm{a}(58.5 \%)$ and allele*1b $(39.5 \%)$. Alleles $* 1 \mathrm{~d}$ and $* 1 \mathrm{f}$ were detected with frequencies of $1.50 \%$, $0.50 \%$, respectively. Of these alleles, there were no significant differences between the two ethnic groups.

Table 1: Frequencies of UGT1A9 polymorphisms in two different ethnic groups of China

\begin{tabular}{|c|c|c|c|c|c|c|c|}
\hline \multirow[b]{2}{*}{ Marker } & \multirow[b]{2}{*}{ Region } & \multirow[b]{2}{*}{$\begin{array}{l}\text { dbSNP } \\
\text { (NCBI) }\end{array}$} & \multirow[b]{2}{*}{ Effect } & \multicolumn{2}{|c|}{ Minor allele frequency $(\%)$} & \multirow[b]{2}{*}{$\begin{array}{l}P \\
\text {-value }\end{array}$} & \multirow[b]{2}{*}{ Flanking sequence } \\
\hline & & & & $\begin{array}{l}\text { Tibetan } \\
(\mathrm{n}=100)\end{array}$ & $\begin{array}{l}\text { Han } \\
(\mathrm{n}=\mathrm{s} 100)\end{array}$ & & \\
\hline$-2189 \mathrm{~T}>\mathrm{C}$ & promoter & novel & & 0.5 & 1.5 & 0.315 & tataatggcgt/cgatctcagct \\
\hline$-1888 \mathrm{~T}>\mathrm{G}$ & promoter & rs6731242 & & 11.0 & 4.5 & $0.015^{* *}$ & actagaagcet/gtaccaataac \\
\hline$-1819 \mathrm{~T}>\mathrm{C}$ & promoter & rs13418420 & & 36.0 & 41.5 & 0.259 & tgtattatcat/caatgaagtca \\
\hline$-441 C>T$ & promoter & rs2741045 & & 3.5 & 2.0 & 0.359 & ttgcttagagc/tatgagttgcc \\
\hline$-332 \mathrm{~T}>\mathrm{C}$ & promoter & rs2741046 & & 4.5 & 6.5 & 0.380 & caaatttactt/cttactttatc \\
\hline-118 delT & promoter & rs 3832043 & & 44.9 & 41.5 & 0.545 & actgattttttttt/-atgaaa \\
\hline$-40 \mathrm{C}>\mathrm{G}$ & promoter & novel & & 0.0 & 0.5 & 0.317 & atcataggagc/gtt AGATTCCC \\
\hline $588 \mathrm{G}>\mathrm{T}$ & Exon1 & novel & $196 \mathrm{G} / \mathrm{G}$ & 2.0 & 0.0 & 0.123 & TTCTCTTAGGG/TTTCTCAGATG \\
\hline $94987 \mathrm{~T}>\mathrm{C}$ & Intron1 & rs6708136 & & 0.5 & 0.0 & 0.317 & atctcaaacac/tgcatgccttt \\
\hline $94990 A>C$ & Intron1 & novel & & 0.5 & 0.0 & 0.317 & tcaaacacgca/ctgcctttaat \\
\hline $95186 \mathrm{G}>\mathrm{A}$ & Exon2 & novel & $314 \mathrm{~K} / \mathrm{K}$ & 0.0 & 1.0 & 0.156 & TTCCAGAGAAG/AAAAGCTATGG \\
\hline $95246 \mathrm{~T}>\mathrm{C}$ & Intron2 & rs4148327 & & 9.5 & 4.5 & $0.05^{* *}$ & gaagattctat/caccatggcct \\
\hline $96292 \mathrm{C}>\mathrm{T}$ & Exon4 & rs34946978 & $361 \mathrm{P} / \mathrm{L}$ & 8.5 & 2.5 & $0.008^{* *}$ & tcag GTCACCC/TGATGACCCGT \\
\hline $96399 \mathrm{~A}>\mathrm{C}$ & Exon4 & novel & $397 \mathrm{~N} / \mathrm{H}$ & 1.0 & 0.0 & 0.156 & TCAGATGGACA/CATGCAAAGCG \\
\hline $100375 \mathrm{C}>\mathrm{T}$ & Exon5 & rs114982090 & 448 P/L & 2.0 & 0.0 & 0.440 & AAGGACCGCCC/TGGTGGAGCCG \\
\hline $100479 \mathrm{~T}>\mathrm{G}$ & Exon5 & rs34993780 & 483 Y/D & 0.0 & 1.5 & 0.079 & CTGGTACCAGT/GACCATTCCTT \\
\hline $100813 \mathrm{~T}>\mathrm{G}$ & 3'UTR & novel & & 0.0 & 0.5 & 0.312 & GTAAAGATATT/GTGAATATGTA \\
\hline $100836 \mathrm{~T}>\mathrm{C}$ & 3'UTR & rs10929303 & & 15.0 & 14.5 & 0.888 & GTGCCCCCTCT/CGGTGTCTTTG \\
\hline $100964 \mathrm{G}>\mathrm{C}$ & 3'UTR & rs 1042640 & & 12.1 & 13.0 & 0.791 & GTGGTCCCACG/CGCTGCCCCTA \\
\hline $101044 \mathrm{~T}>\mathrm{C}$ & 3'UTR & rs 34942353 & & 1.0 & 0.0 & 0.156 & TAACCAATAAT/CGGTCAGTCCT \\
\hline $101065 \mathrm{G}>\mathrm{C}$ & 3'UTR & rs8330 & & 13.0 & 13.5 & 0.883 & CATCTCTGTCG/CTGCTTCATAG \\
\hline
\end{tabular}

${ }^{*}$ The A of the ATG of the initiator Met codon is denoted nucleotide +1 , as recommended by the Nomenclature Working Group (Hum Mut 1998; 11:1-3). The nucleotide sequence (Gene ID: 54600) was used as a reference sequence. $3^{\prime} \mathrm{UTR}, 33^{\prime}$ Untranslated region. ${ }^{\circledR}$ The $P$ value is for the comparison of the minor allele frequencies among the two different ethnic groups of China. ${ }^{* *}$ Significantly different between the Chinese Tibetan and Han population in the present study with $\mathrm{p} \leq 0.05$ 


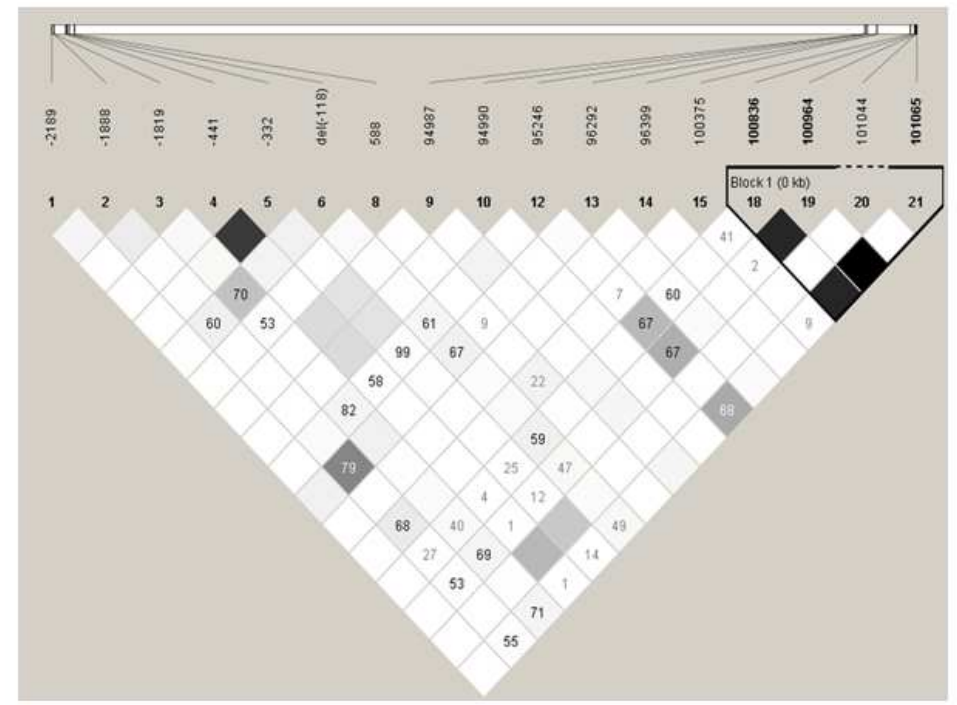

(A)

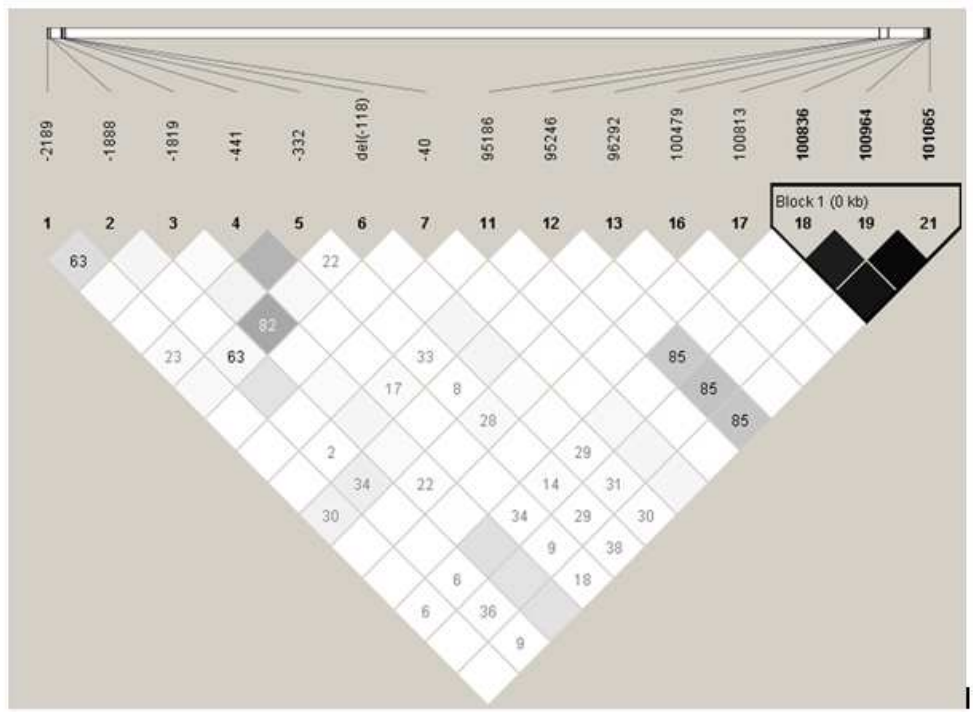

(B)

Fig. 1: Pairwise linkage disequilibrium associations between the SNPs in the UGT1A9 gene in the two ethnic groups of China (A) Tibetan (B) Han. A correlation coefficient $\mathrm{r} 2$ color scheme is used to display LD by a scale of color intensity, black for very strong $\operatorname{LD}(\mathrm{r} 2=1)$, white for no $\mathrm{LD}(\mathrm{r} 2=0)$ and shades of gray for intermediate $\mathrm{LD}(0<\mathrm{r} 2<1)$

Table 2: Frequencies of UGT1A9 allele in two different ethnic groups of China

\begin{tabular}{|c|c|c|c|}
\hline \multirow[b]{2}{*}{ UGT1A9 alleles } & \multicolumn{3}{|c|}{ Allele frequencies (\%) } \\
\hline & Tibetan $(n=100)$ & $\operatorname{Han}(\mathrm{n}=100)$ & ${ }^{*} P$-value \\
\hline *1a(wild) & 55.05 & 58.5 & 0.544 \\
\hline * $1 b$ & 41.41 & 39.5 & 0.759 \\
\hline * $1 d$ & 1.52 & 1.5 & 1.000 \\
\hline *1f & 2.02 & 0.5 & 0.214 \\
\hline
\end{tabular}

\#The $\mathrm{P}$ value is for the comparison of the allele frequencies among the two different ethnic groups of China.
With regard to genotypes, the frequencies of genotypes were listed in Table 3. Seven genotypes were found in this study. In Tibetan population, $55.56 \%$ of the subjects carried one mutated allele which were UGTIA9 $* 1 \mathrm{a} / * 1 \mathrm{~b}(50.51 \%), * 1 \mathrm{a} / * 1 \mathrm{~d}(2.02 \%), * 1 \mathrm{a} / * 1 \mathrm{f}$ $(3.03 \%)$ and $17.17 \%$ carried two defective alleles being homozygous for $* 1 b / * 1 b(15.15 \%)$, heterozygote for $* 1 \mathrm{~b} / * 1 \mathrm{f}$ and $* 1 \mathrm{~b} / * 1 \mathrm{~d}$ with the same frequency of $1.01 \%$. In Han population, $47.00 \%$ of the subjects 
Am. Med. J. 3 (2): 194-202, 2012

carried one mutated allele which were $* 1 \mathrm{a} / * 1 \mathrm{~b}$ $(45.00 \%), * 1 \mathrm{a} / * 1 \mathrm{~d}(2.00 \%)$ and $14.14 \%$ carried two defective alleles being homozygous for UGTIA9 $* 1 \mathrm{~b} / * 1 \mathrm{~b}(16.00 \%) . U G T 1 A 9 * 1 \mathrm{a} / * 1 \mathrm{f}$ was only detected in Han populations. Of these genotypes, there were no significant differences between the two ethnics.

LD/Haplotyping analysis: LD in pairwise SNPs was calculated for the two ethnic groups through Haploview analysis by calculating D' and correlation of alleles at two loci $\left(\mathrm{r}^{2}\right)$. The results were shown in Fig. 1. The results indicated that the degrees of linkage disequilibrium seem to be no different in the two populations.

The haplotype frequencies and htSNPs determination in the two ethnic groups analyzed by Haploview were summarized in Table 4 .
Table 3: Frequencies of UGT1A9 genotypes in two different ethnic groups of China

\begin{tabular}{|c|c|c|c|}
\hline \multirow[b]{2}{*}{ UGT1A7 genotype } & \multicolumn{3}{|l|}{ Frequencies (\%) } \\
\hline & Tibetan $(\mathrm{n}=100)$ & $\operatorname{Han}(n=100)$ & ${ }^{*} P$-value \\
\hline$* 1 \mathrm{a} / * 1 \mathrm{a}$ & $\mathrm{a} 27.27$ & 35 & 0.284 \\
\hline$* 1 \mathrm{a} / * 1 \mathrm{~b}$ & 50.51 & 45 & 0.479 \\
\hline$* 1 \mathrm{a} / * 1 \mathrm{~d}$ & 2.02 & 2 & 1.000 \\
\hline$* 1 \mathrm{a} / * 1 \mathrm{f}$ & 3.03 & 0 & 0.121 \\
\hline$* 1 \mathrm{~b} / * 1 \mathrm{~b}$ & 15.15 & 16 & 1.000 \\
\hline$* 1 \mathrm{~b} / * 1 \mathrm{~d}$ & 1.01 & 1 & 1.000 \\
\hline$* 1 \mathrm{~b} / * 1 \mathrm{f}$ & 1.01 & 1 & 1.000 \\
\hline$* 1 \mathrm{~d} / * 1 \mathrm{~d}$ & 0.00 & 0 & 1.000 \\
\hline$* 1 \mathrm{~d} / * 1 \mathrm{f}$ & 0.00 & 0 & 1.000 \\
\hline$* 1 \mathrm{f} / * 1 \mathrm{f}$ & 0.00 & 0 & 1.000 \\
\hline
\end{tabular}

\begin{tabular}{|c|c|c|c|c|c|}
\hline \multirow[t]{7}{*}{ (a) } & Wild type & -1907 & СTACTGTGCACTAGAAGCCTTACCAATAACAG -1876 & C/EBP\&. & $89.2^{\#}$ \\
\hline & Mutant & -1907 & СTACTGTGCACTAGAAGCCGTACCAATAACAG - 1876 & ** & ** \\
\hline & Wild type & -1839 & TGTTATATACTGTATTATCATAATGAAGTCAG -1808 & Oct-1 & 94.5 \\
\hline & & & * & CdxA & 85.7 \\
\hline & Mutant & -1839 & 9 TGTTATATACTGTATTATCACAATGAAGTCAG -1808 & Nkx-2 & 85.3 \\
\hline & Wild type & -457 & 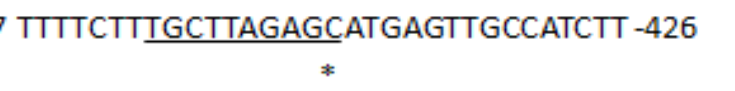 & $\mathrm{CP} 2$ & 85.4 \\
\hline & Mutant & -457 & $\begin{array}{l}7 \text { TTTCTTTGCTTAGAGTATGAGTTGCCATCTT }-426 \\
*\end{array}$ & $* *$ & $* *$ \\
\hline \multirow[t]{6}{*}{ (b) } & h-UGT1A9 & 359 & GHPMTRAF ITHAGSHGVYESICNGVPMVMMPLFGD & QMDNA & 398 \\
\hline & r-UGT1A9 & 361 & GHPK ARAFITH SGSHGIYEGICNGVPMVMMPLFGD & QMDNA & 400 \\
\hline & d-UGT1A9 & 362 & $\begin{array}{l}\text { GHPKVRAFVTHGGSHGIYEGICNGVPMVM L PLFGD } \\
\quad *\end{array}$ & Q G DNA & 401 \\
\hline & h-UGT1A9 & 446 & DRPVEPLDLAVFWVEFVMRHKGAPHLRPAAHDLTWY & YQYHS & 485 \\
\hline & r-UGT1A9 & 448 & DRP I EPLDLAVFWVEYVMRHKGAPHLRPAAHDLTWY & YQYHS & 487 \\
\hline & d-UGT1A9 & 449 & DRPI EPLDLAVFWTEFVMR HKGAEHLRPAAHDLNW & IQYHS & 488 \\
\hline
\end{tabular}

Fig. 2: (a) Human transcriptional factor targeted site in the promoter sequence of UGT1A9 gene. Numbers indicate the position of nucleotide sequence. The asterisks indicate the positions at which mutation occurs. ${ }^{\&}$ transcription factor. ${ }^{\#}$ The score is predicted by TFSEARCH software. Transcriptional factor targeted sites are underlined. **, no transcription factors (b) Alignment of partial amino acid sequences of UGT1A9 from three species including Homo sapiens (h), Rattus norvegicus (r) and Danio rerio (d). Numbers indicate the position of the amino acid sequence. The asterisks indicate the positions at which missense mutations occur (P361L, N397H, P448L and Y483D) 
Am. Med. J. 3 (2): 194-202, 2012

Table 4: Frequencies of haplotypes of the UGT1A9 gene in two different ethnic groups of China

\begin{tabular}{|c|c|c|c|c|}
\hline $\begin{array}{l}\text { Ethnic } \\
\text { groups }\end{array}$ & $\begin{array}{l}\text { SNPs in } \\
\text { haplotypes }\end{array}$ & Haplotypes & $\begin{array}{l}\text { Frequencies } \\
(\%)\end{array}$ & $\begin{array}{l}\text { Tag } \\
\text { SNPs }\end{array}$ \\
\hline \multirow[t]{3}{*}{ Tibetan } & $100836 \mathrm{~T}>\mathrm{C}$ & $\mathrm{CCC}$ & 85.0 & $\begin{array}{l}100836 \mathrm{~T}>\mathrm{C} \\
100964 \mathrm{G}>\mathrm{C}\end{array}$ \\
\hline & $100964 \mathrm{G}>\mathrm{C}$ & TGG & 12.5 & \\
\hline & $101065 \mathrm{G}>\mathrm{C}$ & TCC & 2.0 & \\
\hline \multirow[t]{2}{*}{ Han } & $\begin{array}{l}100836 \mathrm{~T}>\mathrm{C} \\
100964 \mathrm{G}>\mathrm{C}\end{array}$ & $\mathrm{CCC}$ & 85.5 & 100836T >C; \\
\hline & $101065 \mathrm{G}>\mathrm{C}$ & TGG & 13.0 & $100964 \mathrm{G}>\mathrm{C}$ \\
\hline
\end{tabular}

Every ethnic group has only one LD block and the haplotype structures were analyzed by using Haploview (Fig. 1). In the LD block, the two groups had similar haplotype structures. Haplotype CCC was the dominating haplotype with the frequencies of $85.0 \%$, $85.5 \%$, respectively, in Tibetan and Han populations. Haplotype TGG had the frequencies of $12.5 \%, 13 \%$, respectively, in Tibetan and Han populations.

Functional predictions: In the promoter region, the TFSEARCH software analysis showed that some polymorphisms altered transcriptional factor binding efficiency. For-1888T (binding C/EBP transcriptional factor), if the variant occurred, there was no related transcriptional factor in binding to the site. For -1819T (binding Oct-1 and CdxA transcriptional factors), if the variant occurred, transcriptional factor transformed into Nkx-2. For 441C (binding CP2), if the variant occurred, there was no related transcriptional factor binding to the site (Fig. 2). Towards the four nonsynonymous variants in the coding region, BLAST software showed that the four missense mutations (P361L, N397H, P448L, Y483D) occurred in highly conserved among three different species (Homo sapiens, Rattus norvegicus and Danio rerio) as shown in Fig. 2b.

\section{DISCUSSION}

Although many polymorphisms of UGT1A9 have been identified in multi-ethnic groups, there are no relative investigations among the Chinese Tibetan population and comparison with Han population to date. This study conducted a comprehensive analysis of UGT1A9 polymorphisms between the two ethnic groups of China. In this study, of all the 21 genetic variants, the allele frequencies of three common variant $(-1888 \mathrm{~T}>\mathrm{G}, 95246 \mathrm{~T}>\mathrm{C}, 96292 \mathrm{C}>\mathrm{T})$ were significantly different between Tibetan and Han population $(\mathrm{p} \leq 0.05)$. Moreover, we also detected some ethnic-specific variants. For instance, $588 \mathrm{G}>\mathrm{T}, \quad 94987 \mathrm{~T}>\mathrm{C}$,
94990A $>C$, 96399A $>C(N 397 H), 100375 C>T(P 448 L)$, $101044 \mathrm{~T}>\mathrm{C}$ were detected only in Tibetan population, while $-40 \mathrm{C}>\mathrm{G}, \quad 95186 \mathrm{G}>\mathrm{A}, \quad 100479 \mathrm{~T}>\mathrm{G} \quad(\mathrm{Y} 483 \mathrm{D})$, $100813 \mathrm{~T}>\mathrm{G}$ only in Han population. Despite that three nonsynonymous variants [8G>A $\quad(\mathrm{C} 3 \mathrm{Y}), \quad 98 \mathrm{~T}>\mathrm{C}$ $(\mathrm{M} 33 \mathrm{~T})$ and $766 \mathrm{G}>\mathrm{A}(\mathrm{D} 256 \mathrm{~N})]$ and a variant at $726 \mathrm{~T}>\mathrm{G}$ resulting in a premature termination codon TAG (Y242X) have been reported in exon1 in other ethnic groups (http://www.pharmacogenomics.pha.ulaval.ca/sgc/ugt_a lleles), we have not detected these variants in this study. Taken together, there are ethnic differences in polymorphic and prevailing mutations of UGT1A9.

$U G T 1 A 9^{*} 1 \mathrm{~b}$, a functional and prevalent defective allele identified in our study, occured at the frequencies of $41.41 \%, 39.50 \%$ in Tibetan and Han populations, respectively. UGT1A9*2 (C3Y)、UGT1A9*3 (M33T), $U G T 1 A 9 * 4(\mathrm{Y} 242 \mathrm{X})$ and $U G T 1 A 9 * 5(\mathrm{D} 256 \mathrm{~N})$, which were identified in other ethnic groups (Ehmer et al., 2004; Villeneuve et al., 2003; Jinno et al., 2003; Saeki et $a l ., 2003)$ were not detected in the present study. These results showed that different genetic polymorphisms of UGT1A9 existed in inter-ethnics.

We analyzed the LD pattern of the two ethnic groups separately. Strong LD was observed among $100836 \mathrm{~T}>\mathrm{C}, 100964 \mathrm{G}>\mathrm{C}, 101065 \mathrm{G}>\mathrm{C}$ in the two populations. The results indicated that the degrees of linkage disequilibrium seem to be no different in the two populations.

Owing to the different htSNPs selection, the different haplotypes structures were made and with a different haplotypes distributions in different populations. The combined effects of some decreasedfunction variants will lead to inactive enzymes. Different polymorphisms and their combinations may generate markedly different results with respect to UGT1A9 activity. Thus, according to htSNPs detection and haplotype analysis the metabolizer phenotype would be identified easily (Chen et al., 2008).

There existed no significant differences in LD pattern, haplotypes and htSNPs between the two populations. Since these parameters could fluctuate owing to small sample sizes, it should increase the number of the study samples to get precise information. It is known that TFs, regulate gene expression by identifying and combining gene promoter cis-regulatory elements. Web-based TFSEARCH (version1.3) was used to analyze the TFs binding. Software analysis showed $-1888 \mathrm{~T}>\mathrm{G},-1819 \mathrm{~T}>\mathrm{C}$ and $-441 \mathrm{C}>\mathrm{T}$ affected the transcriptional factor binding, leading to conversions from $\mathrm{C} / \mathrm{EBP}$ binding site to none, from Oct-1, CdxA to Nkx-2 and from CP2 to none (Fig. 2). Further investigations are needed to confirm the impact 
on the gene expression. Apart from the known functional variants $U G T 1 A 9^{*} 1 \mathrm{~b}, * 1 \mathrm{~d}, * 1 \mathrm{f}$, we conducted the conservative assessment of other variants by the web-based Protein BLAST software. Four of the missense mutations (P361L, N397H, P448L and Y483D) occurred in highly conserved among three different species. The result indicates that these mutations may give rise to significant effects on the function of UGT1A9. In order to determine the effects, further functional researches should be done.

Glucuronidation, catalyzed by UDP-Glucuronosyl Transferases (UGTs), is one of the critical steps in the detoxification and elimination of various endogenous and exogenous compounds. Some of the polymorphisms of UGTs isoforms are known to affect glucuronidation rates (Radominska et al., 1999; Tukey and Strassburg, 2001). Numerous studies of functional characterizations of UGTIA9 polymorphisms which may be associated with altered metabolism/pharmacokinetics of certain drugs have been conducted. The SN-38, the active antitumor metabolite of the irinotecan (a main therapeutic drug for the treatment of metastatic colorectal cancer patients), is detoxified by UGTIA isoforms. Previous studies have shown that $U G T 1 A 9^{*} 1 \mathrm{~b}$ with impaired enzyme function have the major effect on the SN-38 detoxification (Gagné et al., 2002; Cecchin et al., 2009). UGT1A9 enzyme variant M33T, heterologously expressed in HEK293 cells, showed 1.7-fold reduced intrinsic clearance for mycophenolic acid 7-O-glucuronide (Bernard and Guillemette, 2004) and 26-fold reduced intrinsic clearance for $\mathrm{SN}-38$ glucuronide (Villeneuve et al., 2003). Another UGT1A9 enzyme variant $\mathrm{D} 256 \mathrm{~N}$, showed 22-fold reduced intrinsic clearance for $\mathrm{SN}-38$ glucuronide (Jinno et al., 2003). Besides, -118(dT), one of the UGTIA9 polymorphisms in the promoter region increased tumor response. $-118(\mathrm{dT})_{9 / 9}$ genotype was significantly associated with efficacious tumor response when compared with all other genotypes and also associated with a lower incidence of toxicity, whereas the $-118(\mathrm{dT})_{10 / 10}$ genotype predicted for poor tumor response (Carlini et al., 2005). Thus, these data have important public health implications. Clinical testing for the UGTIA9 polymorphisms should be implemented as predictors of toxicity/effectiveness of some drugs. In this regard, systematically studying the polymorphisms of UGTIA9 might play an important role in the prediction of toxicity and responsiveness to cytotoxic agents, as described for other detoxifying enzymes (Martino et al., 2011).

\section{CONCLUSION}

In conclusion, our results showed that there are ethnic differences in polymorphic and prevailing mutations of UGT1A9 in Chinese Tibetan and Han populations. The predicted potential variants $96292 \mathrm{C}>\mathrm{T}$ (P361L), 96399A $>\mathrm{C} \quad(\mathrm{N} 397 \mathrm{H}), \quad 100375 \mathrm{C}>\mathrm{T} \quad(\mathrm{P} 448 \mathrm{~L})$, $100479 \mathrm{~T}>\mathrm{G}$ (Y483D) may be functional variants. Our data may serve as a baseline for large samples studies on pharmacogenomics and also provide important data for the advance of personalized medicine in Chinese Han and Tibetan populations.

\section{ACKNOWLEDGEMENT}

We are grateful to all the participants in this study. This study was supported by a grant from the National High Technology Research and Development Program of China (863 Program) (No. 2009AA022710). We would like to express our sincere gratitude to Changfeng Li for his technical support for our study.

\section{REFERENCES}

Albert, C., M. Vallée, G. Beaudry, A. Bélanger and D.W. Hum, 1999. The monkey and human uridine diphosphate-glucuronosyltransferase UGTIA9, expressed in steroid target tissues, are estrogenconjugating enzymes. Endocrinology, 140: 32923302. DOI: 10.1210/en.140.7.3292

Araki, J., Y. Kobayashi, M. Iwasa, N. Urawa and E.C. Gabazza et al., 2005. Polymorphism of UDPglucuronosyltransferase 1A7 gene: A possible new risk factor for lung cancer. Eur. J. Cancer, 41: 2360-2365. DOI: 10.1016/j.ejca.2005.04.043

Bernard, O. and C. Guillemette, 2004. The main role of UGTIA9 in the hepatic metabolism of mycophenolic acid and the effects of naturally occurring variants. Drug Metab Dispos, 32:775778. PMID: 15258099

Carlini, L.E., N.J. Meropol, J. Bever, M.L. Andria and T. Hill et al., 2005. UGT1A7 and UGT1A9 polymorphisms predict response and toxicity in colorectal cancer patients treated with capecitabine/irinotecan. Clin. Cancer Res., 11: 1226-1236. PMID: 15709193

Cecchin, E., F. Innocenti, M. D'Andrea, G. Corona and E.D., Mattia et al., 2009. Predictive role of the UGT1A1, UGTIA7 and UGTIA9 genetic variants and their haplotypes on the outcome of metastatic colorectal cancer patients treated with fluorouracil, leucovorin and irinotecan. J. Clin. Oncol., 27: 2457-2465. DOI: 10.1200/JCO.2008.19.0314 
Chen, L.L., S.Y. Qin, J. Xie, J.M. Tang and L. Yang et al., 2008. Genetic polymorphism analysis of CYP2C19 in Chinese Han populations from different geographic areas of mainland China. Pharmacogenomics, 9: 691-702. DOI: 10.2217/14622416.9.6.691

Chouinard, S., M. Tessier, G. Vernouillet, S. Gauthier and F. Labrie et al., 2006. Inactivation of the pure antiestrogen fulvestrant and other synthetic estrogen molecules by UDPGlucuronosyltransferase 1A enzymes expressed in breast tissue. Mol. Pharmacol.., 69: 908-920. DOI: 10.1124/mol.105.015891

Ehmer, U., A. Vogel, J.K. Schütte, B. Krone and M.P. Manns et al., 2004. Variation of hepatic glucuronidation: Novel functional polymorphisms of the UDP-glucuronosyltransferase UGT1A4. Hepatology., 39: 970-977. DOI: 10.1002/hep. 20131

Fujita, K., Y. Ando, F. Nagashima, W. Yamamoto and H. Endo et al., 2006. Novel single nucleotide polymorphism of UGT1A7 Gene in Japanese. Drug Metab. Pharmacokinet., 21: 75-78. DOI: 10.2133/dmpk.21.75

Gagné, J.F., V., P. Belanger, K. Journault, G. Gaucher and C. Guillemette, 2002. Common human UGT1A polymorphisms and the altered metabolism of irinotecan active metabolite 7-ethyl-10hydroxycamptothecin (SN-38). Mol. Pharmacol., 62: 608-617. DOI: 10.1124/mol.62.3.608

Gong, Q.H., J.W. Cho, T. Huang, C. Potter and N. Gholami et al., 2001. Thirteen UDPglucuronosyltransferase genes are encoded at the human UGT1 gene complex locus. Pharmacogenetics, 11: 357-368. DOI: 10.1097/00008571-200106000-00011

Han, J.Y., H.S. Lim, E.S. Shin, Y.K. Yoo and Y.H. Park et al., 2006. Comprehensive analysis of UGT1A polymorphisms predictive for pharmacokinetics and treatment outcome in patients with non-smallcell lung cancer treated with irinotecan and cisplatin. J. Clin. Oncol., 24: 2237-2244. DOI: 10.1200/JCO.2005.03.0239

Hill, W.G. and A. Robertson, 1968. The effects of inbreeding at loci with heterozygote advantage. Genetics., 60: 615-628. PMID: 5728744

Jinno, H., M. Saeki, Y. Saito, K.T. Tanaka and N. Hanioka et al., 2003. Functional characterization of human UDP-glucuronosyltransferase 1A9 variant, $\mathrm{D} 256 \mathrm{~N}$, found in Japanese cancer patients. J. Pharmacol. Exp. Ther., 306: 688-693. DOI: 10.1124/jpet.103.051250
Lewontin, R.C. 1988. On measures of gametic disequilibrium. Genetics, 120: 849-852. PMID: 3224810

Martino, M.T.D., M. Arbitrio, E. Leone, P.H. Guzzi and M.S. Rotundo et al., 2011. Single nucleotide polymorphisms of ABCC5 and ABCG1 transporter genes correlate to irinotecan-associated gastrointestinal toxicity in colorectal cancer patients: A DMET microarray profiling study. Cancer Biol. Ther., 12: 780-787. DOI: 10.4161/cbt.12.9.17781

Mehlotra, R.K., M.J. Bockarie and P.A. Zimmerman, 2007. Prevalence of UGT1A9 and UGT2B7 nonsynonymous single nucleotide polymorphisms in West African, Papua New Guinean and North American populations. Eur. J. Clin. Pharmacol., 63: 1-8. DOI:10.1007/s00228-006-0206-z

Radominska, P.A., P.J. Czernik, J.M. Little, E. Battaglia and P.I. Mackenzie, 1999. Structural and functional studies of UDP-glucuronosyltransferases. Drug Metab Rev., 31: 817-899. DOI: 10.1081/DMR100101944

Saeki, M., Y. Saito, H. Jinno, K. Sai and K. Komamura et al., 2003. Three novel single nucleotide polymorphisms in UGT1A9. Drug Metab. Pharmacokinet., 18: 146-149. DOI: 10.2133/dmpk. 18.146

Stephens, M., N.J. Smith and P. Donnelly, 2001. A new statistical method for haplotype reconstruction from population data. Am. J. Hum. Genet., 68: 978-989. DOI: $10.1086 / 319501$

Strassburg, C.P., K. Oldhafer, M.P. Manns and R.H. Tukey, 1997. Differential expression of the UGTIA locus in human liver, Biliary and gastric tissue: identification of UGT1A7 and UGT1A10 transcripts in extrahepatic tissue. Mol Pharmacol., 52: 212-220. PMID: 9271343

Strassburg, C.P., N. Nguyen, M.P. Manns and R.H. Tukey, 1998. Polymorphic expression of the UDPglucuronosyltransferase UGT1A gene locus in human gastric epithelium. Mol Pharmacol., 54: 647-654. PMID: 9765507

Strassburg, C.P., N. Nguyen, M.P. Manns and R.H. Tukey, 1999. UDP-glucuronosyltransferase activity in human liver and colon. Gastroenterology. 116: 149-160.

Tukey, R.H. and C.P. Strassburg, 2000. Human UDPglucuronosyltransferases: Metabolism, expression and disease. Annu. Rev. Pharmacol. Toxicol., 40: 581-616. DOI: 10.1146/annurev.pharmtox.40.1.581

Tukey, R.H. and C.P. Strassburg, 2001. Genetic Multiplicity of the human UDPGlucuronosyltransferases and regulation in the gastrointestinal tract. Mol. Pharmacol., 59: 405414. PMID: 11179432 
Turgeon, D., J.S. Carrier, E. Lévesque, B.G.. Beatty, A. Bélanger and D.W. Hum, 2000. Isolation and characterization of the human UGT2B15 gene, localized within a cluster of UGT2B genes and pseudogenes on chromosome 4. J Mol Biol., 295: 489-504. DOI: 10.1006/jmbi.1999.3374

Villeneuve, L., H. Girard, L.C. Fortier, J.F. Gagne and C. Guillemette, 2003. Novel functional polymorphisms in the UGT1A7 and UGT1A9 glucuronidating enzymes in Caucasian and African-American subjects and their impact on the metabolism of 7-Ethyl-10-hydroxycamptothecin and flavopiridol anticancer drugs. J. Pharmacol. Exp. Ther., 307: 117-128. DOI: 10.1124/jpet.103.054072
Vogel, A., J. Ockenga, U. Ehmer, A. Barut and F.J. Kramer et al., 2002. Polymorphisms of the carcinogen detoxifying UDPglucuronosyltransferase UGT1A7 in proximal digestive tract cancer. $\mathrm{Z}$ Gastroenterol, 40: 497502. DOI: $10.1055 / \mathrm{s}-2002-32805$

Yamanaka, H., M. Nakajima, M. Katoh, Y. Hara and O. Tachibana et al., 2004. A novel polymorphism in the promoter region of human UGT1A9 gene $\left(U G T 1 A 9^{*} 22\right)$ and its effects on the transcriptional activity. Pharmacogenetics, 14: 329-332. PMID: 15115919 